\title{
A quantitative measure of restricted and repetitive behaviors for early childhood
}

\author{
Jason J. Wolff ${ }^{*}$, Brian A. Boyd ${ }^{2}$ and Jed T. Elison ${ }^{3}$
}

\begin{abstract}
Background: Restricted and repetitive behaviors are characteristic phenotypic features of many neurodevelopmental, psychiatric, and neurological conditions. During early childhood, such behaviors are considered normative. More research is needed to delineate the dimensions of restricted and repetitive behavior across typical and atypical development during this period.

Methods: We developed the 34-item parent-rated Repetitive Behavior Scale for Early Childhood (RBS-EC) to capture quantitative, dimensional features across a broad range of behaviors contributing to this domain. We evaluated its psychometric properties and factor structure in a community sample of 914 toddlers.

Results: The RBS-EC showed excellent overall internal consistency $(a=0.90)$, strong test-retest reliability (ICC $=0.87$ for topographies and 0.90 for frequency) and evidence of convergent and discriminative validity. Using a split-half approach to factor analysis, we identified that a three- or four-factor structure best fit the data and confirmatory factor analysis indicated acceptable fit for both models. The empirically derived four-factor model was consistent with our conceptual model and included repetitive motor, restricted interests and behavior, ritual and routine, and self-directed behavior.

Conclusions: This initial study indicates that the RBS-EC is a reliable and valid instrument for characterizing quantitative, dimensional aspects of restricted and repetitive behaviors in young children.
\end{abstract}

Keywords: Repetitive behavior, Motor stereotypy, Circumscribed interests, Ritualistic behavior, Self-injurious behavior, Measurement, Toddlers

Abbreviations: ASD, autism spectrum disorder; RBS-EC, Repetitive Behavior Scale for Early Childhood; RBS-R, Repetitive Behavior Scale, Revised; RRB, restricted and repetitive behavior; vrRSB, Video-Referenced Rating of Reciprocal Social Behavior

\section{Background}

Restricted and repetitive behaviors (RRBs) denote a broad class of behavior characterized by repetition and invariance. This includes motor stereotypies, compulsive and ritualistic behaviors, repetitive self-injury, and inflexibility and rigidity, as well as circumscribed and intense interests or activities. Though a diagnostic feature of autism spectrum disorder, RRBs also contribute to the distinctive behavioral phenotypes of many etiologically defined as well as idiopathic neurodevelopmental disorders [1-3]. Restricted and repetitive behaviors are likewise

\footnotetext{
* Correspondence: jjwolff@umn.edu

'Department of Educational Psychology, University of Minnesota, Minneapolis, MN, USA

Full list of author information is available at the end of the article
}

associated with psychiatric and neurological conditions, such as stereotypic movement disorder, obsessivecompulsive and related disorders, Tourette's syndrome, Parkinson's disease, and anorexia nervosa [4-7]. The behavioral topographies constituting the domain of RRBs occur in patterns which may differentiate these diagnostic categories as well as cut across them [1-3, 8].

The presence of RRBs is not unique to pathological conditions. Such behaviors also occur over the entire course of normative human and nonhuman development [9-11]. This is most evident in early childhood, as typically developing children express a range of RRBs from infancy through school age. In human infants and toddlers, motor stereotypies are quite common and develop in progressive fashion, likely supporting the 
acquisition of increasingly sophisticated behavioral output [12-14]. Rigid and ritualistic patterns of behavior such as strict adherence to daily routines or insistence on sameness with regard to their environment and activities may be observed from toddlerhood through early school age $[15,16]$. Other repetitive behavior topographies such as skin picking or finger/thumb sucking may continue into later childhood and have been associated with factors such as mood, arousal, and child maltreatment $[17,18]$. While not conclusive, available evidence suggests that individual differences in early life restricted and repetitive behaviors may predict adaptive behavior, anxiety, temperament, and later emerging psychopathology $[16,19,20]$.

A central challenge to better understand the relevance of early RRBs to clinical outcomes has been our inability to measure dimensionality in the manifestation of these behaviors, from typical to atypical, during a time of rapid development. Clinically oriented measures such as the Autism Diagnostic Interview-Revised [21] or Children's Yale-Brown Obsessive Compulsive Scale [22], which include repetitive behavior items, are excellent for diagnostic purposes but are not designed to detect dimensional features of behavior that may be continuously distributed across individuals early in development. Automated [23-25] or direct-observation and video coding procedures [12, 14, 26, 27] are direct approaches to measuring RRBs which can yield highly dimensional data. However, these methods are typically costly and labor intensive and have generally been limited to measurement of motor stereotypies or self-injurious behaviors. Informant-based questionnaires are a viable alternative given that they are less costly to administer and more time efficient. Questionnaire measures of RRBs [15, 17, 28, 29], while more subjective and subject to bias, are also capable of capturing a wider range of behavioral topographies relative to direct measures.

The Repetitive Behavior Scale-Revised (RBS-R; [28]) is among the most widely implemented of such measures and has been used across a broad age range [30, 31], including early childhood [3, 13, 32, 33]. The RBS-R is comprised of 43 items, with each gauging presence or absence of behavior and its perceived severity. The measure groups items into six subscales, though several independent analyses have suggested alternative factor structures [31, 32, 34]. There are limitations to the RBS-R in early childhood samples, however, as it is ultimately a clinical severity measure which yields scores characterized by significant floor effects among typically developing children or children for whom a clinical condition may not be obvious or fully manifest [33].

In this study, we describe a newly developed parent- orcaregiver rated measure of restricted and repetitive behaviors specifically designed for use in early childhood. Our goal was to create a measure that was similar in structure to the RBS-R but tailored for use in early childhood. We further sought to maximize dimensional yield by constructing a measure that captures ordinal frequency information across the many behavioral topographies comprising the repetitive behavior domain. Here, we report initial psychometric and factor analyses of this new measure based on data collected from a community sample of 914 toddlers.

\section{Methods \\ Measure development}

Measure development was initiated and led by the first author in consultation with the second. Items were first derived from the RBS-R [28] and subsequently pooled with those from two versions of the Repetitive Behavior Questionnaire [29, 35] to check for construct overlap and to identify potential additional items. Nearly all items appearing on the Repetitive Behavior Questionnaire were deemed to have a counterpart item on the RBS-R with the exception of one item concerning unusual visual inspection of objects. Items were retained for revision based on the authors' previous experience and if they were consistent with published literature reporting or describing such behaviors in typically developing children or children with a neurodevelopmental disorder [12, 14$17,19,29,33,36-38]$. Items were excluded if their content was deemed age inappropriate, such as item 26 from the RBS-R regarding inflexibility related to travel and transportation. Some items reflecting more adultoriented compulsive behavior from the RBS-R were also excluded given developmental relevance and evidence of significant floor effects among young children [33]. This included compulsivity items reflecting excessive cleaning, checking locks or doors, or counting. The revision process of items retained from the RBS-R included changes to terminology and/or item descriptions, such as the inclusion of the descriptors related to toys, "melt downs," or other age appropriate objects and activities. For example, item 36 from the RBS-R, "Likes same CD, tape, record..." was revised as "Restricted use of media." with reference to more contemporary media commonly used by children, such as mobile apps. New items were developed upon the basis of published work characterizing repetitive behaviors among infants, toddlers, and preschool/school aged children with and without a neurodevelopmental disorder $[12,14,15,33,36]$. This included items related to inflexible social interactions, unusual visual inspection, restricted movement or stillness, mouthing of objects, and more refined categories of motor stereotypies. These initial development steps culminated in a measure comprised of 41 items.

In order to better capture dimensionality among children for whom some degree of RRBs is expected, we avoided the use of clinical terminology or the framing of RRBs as problem behavior. All item descriptions were 
written to be consistent across the measure, developmentally appropriate for young children based on the authors' expertise in repetitive behaviors and child development, and neutral with regard to behaviors as disruptive. Terms such as "stereotyped," "compulsive," "self-injurious," and "sameness" were replaced with language deemed less clinical. In place of the four-level severity scale used by the RBS-R, a five-level rating scale was developed to gauge frequency of occurrence for each item over the previous month. This scale consisted of the following: 0-behavior does not occur, 1-behavior occurs about weekly or less, 2-behavior occurs several times a week, 3-behavior occurs about daily, and 4-behavior occurs many times a day. Each item contributes to two measures: topographies endorsed and frequency score. These measures may be summed into total or conceptually derived subscale scores. Initial subscales included repetitive motor, ritual and routine, restricted behavior, and self-directed behavior. Self-directed items reflect behaviors which may be considered selfinjurious in some contexts but that in early childhood may not be associated with tissue damage or a behavioral disorder per se [17, 39].

Following item development by the study authors, content and face validity were assessed by obtaining outside feedback from experts in RRBs as well as overlapping areas/constructs including early child development, motor development, measurement, and autism spectrum disorder. Content experts were contacted by email and were asked to review the measure and respond to a set of open-ended survey questions. Feedback was also elicited from a group of parents $(n=8)$ who read an initial version of the measure, completed a brief set of openended questions, and discussed its content with the first author. Based on this external feedback, the measure was revised yielding the version presently under study-the Repetitive Behavior Scale for Early Childhood (RBS-EC). Approval for duplicate use of the name "Repetitive Behavior Scale" was obtained from the primary author of the RBS-R. Instructions accompanying the RBS-EC, as well as sample items, are provided in Additional file 1.

\section{Participants and procedures}

Data collection occurred between May and October 2015. Parents of toddlers between 17 and 25 months of age, recruited from the Institute of Child Development (ICD) research participant registry, were invited to participate in a larger study about their child's development. All parents of 17-25 months old during the study period were invited to participate, unless they had a toddler in the age range who was an active participant in an ongoing study conducted by ICD faculty or if their toddler had participated in a study in the previous 6 months. The ICD registry personnel acquire Minnesota birth records and invite parents to voluntarily select into the
ICD Infant Participant Pool. The registry largely reflects the racial/ethnic proportions of the broader MinneapolisSt. Paul metropolitan area but under-represents the socioeconomic diversity of this region. As part of the larger study, parents were invited to complete a form characterizing demographic and family characteristics, the VideoReferenced Rating of Reciprocal Social Behavior (vr-RSB) [40], the RBS-EC, and the MacArthur-Bates Communicative Development Inventories [41], in that order. All data collection occurred online [42], and it took parents $\sim 45 \mathrm{~min}$ to complete the entire survey battery. Following the extant literature on survey research strategies [43], 2-3 days before receiving the online consent and questionnaires via email, parents were sent an introductory email describing the research. Parents were reimbursed with a \$10 electronic gift card, and their name was entered into a drawing for a $\$ 50$ electronic gift card (1 per 150 completed surveys) if they completed all of the questionnaires. Two follow-up emails were sent, 1 - and then 2-weeks following the initial email, inviting parents to participate OR to complete forms if they had started but not finished the survey battery. All parents provided permission and informed consent to participate in the study. There were no exclusion criteria. Of the 2486 parents invited to contribute, 933 (38\%) completed the vr-RSB and RBS-EC questionnaires. As compared to the demographic characteristics of the children between 2 and 60 months in the ICD Infant Participant Pool, those who completed the surveys reported similar proportions of race/ethnicity classifications, but a higher household income (i.e., a lower proportion of responders reported household incomes between 25 and $75 \mathrm{~K}$ and a greater proportion of responders reported household income more than $200 \mathrm{~K})$. Characteristics of the sample are given in Table 1. Nineteen participants were excluded for providing responses that suggested invalid data (e.g., time to complete the entire in survey was less than $1 \mathrm{~min}$ ). Study procedures were approved by the University of Minnesota Institutional Review Board (\#1501S61261) and informed written consent was obtained from each participant.

\section{Parent-report questionnaires}

The Video-Referenced Rating of Reciprocal Social Behavior, version 2.3 [40] represents a downward extension of the Social Responsiveness Scale, second edition (SRS-2) [44]. The first 13 items (out of a total of 48 items) are scored in reference to a 3-min video of a typically developing 19 month-old child demonstrating a variety of reciprocal social behaviors (e.g., expressing feelings through changes in facial expression, cooperating with adult's request, and performing showing and requesting behaviors). Thirty-five additional questions reflect quantitative aspects of social behavior and two final questions ask the parent to report specifically about the number of words 
Table 1 Descriptive and demographic data for study sample

\begin{tabular}{lllll}
\hline Variable & Number & Percent & Mean & (SD) \\
\hline Age in months & 914 & & 19.7 & $(2.4)$ \\
Gestational age (days) & $783^{\mathrm{a}}$ & & 275.2 & $(14.2)$ \\
$\begin{array}{l}\text { Birth weight (grams) } \\
\text { Sex }\end{array}$ & $895^{\mathrm{a}}$ & & 3493 & $(540)$ \\
$\quad$ Females & 442 & 48 & & \\
$\quad$ Males & 472 & 52 & & \\
Race/ethnicity & & & & \\
$\quad$ White & 814 & 89 & & \\
$\quad$ Non-white or mixed & 100 & 11 & & \\
Parent's education & & & \\
$\quad$ Some college or less & 113 & 12 & \\
College degree & 429 & 47 & \\
$\quad$ Graduate degree & 372 & 41 & \\
\hline
\end{tabular}

${ }^{a}$ Gestational age and birth weight data not available for all cases

produced by the child and to provide an example of a complex/sophisticated sentence produced by their child. The instrument takes $\sim 15-20$ min to complete. An initial study documented appropriate test-retest reliability, modest convergent validity with a measure of social communicative development and high concordance among monozygotic twins as compared to dizygotic twins [40]. As previously reported, a total summary score and a summary score of the video-referenced items only can be derived. The vr-RSB items can also be conceptually grouped into social and repetitive domains (correspondence between the JTE and N. Marrus), and these domain scores, along with video-referenced reciprocal social behavior scores, were derived to examine convergent and divergent validity with the RBS-EC. As the focus of this analysis is on the initial description of the RBS-EC, a full analysis of the vr-RSB data will be described in a subsequent publication.

The Repetitive Behavior Scale for Early Childhood has been described above.

\section{Analysis}

Mann-Whitney $U$ tests were used to examine sex differences in RBS-EC total and subscale scores. Test-retest reliability was assessed by intraclass correlations of data from a subset $(n=46)$ of the total sample. Internal consistency of RBS-EC composite and subscale measures was assessed by Chronbach's alpha. Convergent and divergent validity were assessed using correlations between overall scores from the RBS-EC and separate measures of social and repetitive behavior from the vr-RSB. Because data did not meet the primary assumptions for parametric analysis, Spearman rank-order correlations were used.
To further assess construct validity, we employed a two-stage factor analytic strategy, starting with exploratory and proceeding to confirmatory factor analysis using a split-half approach. Exploratory factor analysis (EFA) was conducted on the first split-half to characterize the item-level factor structure of the RBS-EC. These analyses used a maximum likelihood extraction method with oblique (promax) rotation. To determine the number of factors to extract, scree plots were generated and examined. Next, we used confirmatory factor analysis to test models derived from the EFA. A cutoff of 0.35 was used to determine items retained within models from the EFA. We also tested the conceptually derived model which formulated the original subscales of the RBS-EC. Model fit statistics include the comparative fit index (CFI), root mean square error of approximation (RMSEA), and standardized root mean square residual (SRMR). Models with adequate-to-good fit are indicated by CFI close to 0.95 (or $>0.90$ ), RMSEA $<0.60$, and SRMR $<0.80[45,46]$. Analyses were performed using IBM SPSS, version 23.

\section{Results}

Table 1 provides descriptive and demographic data for the study sample. Of the total study sample $(n=914), 442$ were female ( $48 \%)$. The average age of participants was 19.7 months $(S D=2.4)$ with a range of 17 to 27 months. Gestational age data were available for $86 \%(n=783)$ of our sample, and approximately $9 \%(n=70)$ of these children had gestational ages of $\leq 36$ weeks.

The average RBS-EC composite topography score for the sample was $12(S D=6.7)$, and the average composite frequency score was 24.6 (16.7). Males and females differed significantly in composite frequency score $(U=$ 95,833, $Z=2.1, p=0.03$ ) but not composite topographies $(U=98,436, Z=1.5, p=0.14)$.

Among subscales, there were sex differences in restricted behavior frequency $(U=92,697, Z=2.9, p=$ $0.003)$ and topographies $(U=93,916, Z=2.6, p=0.008)$, with males having higher scores. There were no sex differences in scores for the other three subscales (all $p>$ 0.12). Complete RBS-EC total and subscale scores are presented in Table 2. Graphed response distributions for subscale topographies endorsed and frequency scores are presented in Additional file 2: Figures S1 and Additional file 3: Figure S2.

\section{Reliability}

Test-retest data were available for $5 \%(n=46)$ of the total sample. Retesting was completed within 3 weeks of the initial administration, with the median retesting taking place at 7 days out (range 1 to 19 days). Intraclass correlation coefficients between scoring administrations were 0.87 for total score (topographies endorsed) and 0.90 for total frequency score. With regard to internal 
Table 2 Repetitive Behavior Scale for Early Childhood composite and subscale scores

\begin{tabular}{|c|c|c|c|c|c|c|c|}
\hline \multirow[b]{2}{*}{ RBS-EC scale } & \multirow{2}{*}{$\begin{array}{l}\text { Scoring scale } \\
\mathrm{Min} / \mathrm{max}\end{array}$} & \multicolumn{2}{|c|}{ Total sample $(n=914)$} & \multicolumn{2}{|c|}{ Females $(n=442)$} & \multicolumn{2}{|c|}{ Males $(n=472)$} \\
\hline & & Mean & SD & Mean & SD & Mean & SD \\
\hline Composite topographies & $0 / 34$ & 12.0 & 6.7 & 11.6 & 6.8 & 12.3 & 6.6 \\
\hline Repetitive motor topographies & $0 / 9$ & 5.8 & 3.0 & 5.7 & 3.1 & 5.9 & 3.0 \\
\hline Ritual and routine topographies & $0 / 10$ & 2.0 & 2.0 & 2.0 & 2.1 & 2.0 & 1.9 \\
\hline Restricted topographies & $0 / 8$ & 2.6 & 2.2 & $2.4^{\mathrm{a}}$ & 2.2 & $2.7^{\mathrm{a}}$ & 2.2 \\
\hline Self-directed topographies & $0 / 7$ & 1.6 & 17 & 1.6 & 1.8 & 1.6 & 1.6 \\
\hline Composite frequency & $0 / 136$ & 24.6 & 16.7 & $23.3^{\mathrm{a}}$ & 16.1 & $25.8^{\mathrm{a}}$ & 17.1 \\
\hline Repetitive motor frequency & $0 / 36$ & 15.2 & 11.2 & 14.6 & 11.3 & 15.7 & 11.2 \\
\hline Ritual and routine frequency & $0 / 40$ & 2.9 & 3.5 & 2.7 & 3.1 & 3.1 & 3.8 \\
\hline Restricted frequency & $0 / 32$ & 4.3 & 4.4 & $3.8^{\mathrm{a}}$ & 4.1 & $4.7^{\mathrm{a}}$ & 4.7 \\
\hline Self-directed frequency & $0 / 28$ & 2.2 & 2.7 & 2.1 & 2.7 & 2.2 & 2.7 \\
\hline
\end{tabular}

${ }^{\mathrm{a}}$ Sex difference statistically significant at $p<0.05$

consistency, Chronbach's alpha for the RBS-EC as a whole was 0.90 . Among the four conceptually derived subscales, Chronbach's apha values were all within the acceptable range with 0.93 for repetitive motor ( 9 items), 0.75 for ritual and routine (10 items), 0.77 for restricted behavior ( 8 items), and 0.70 for self-directed (6 items).

\section{Construct validity}

In terms of convergent validity, repetitive behaviors measured by the vr-RSB significantly correlated with total composite score $\left(r_{s}=0.43, p<0.001\right)$ and total frequency score $\left(r_{\mathrm{s}}=0.39, p<0.001\right)$ on the RBS-EC. For discriminant validity, summary scores from video-referenced items on the vr-RSB did not correlate with total composite or total frequency scores from the RBS-EC $\left(r_{\mathrm{s}}<0.02, p>\right.$ $0.65)$. However, both the total composite and total frequency scores from the RBS-EC did correlate weakly but statistically significantly with social-communication summary scores from the vr-RSB, $r_{\mathrm{s}}=0.17, p<0.001$ (note that higher scores on the vr-RSB reflect less sophisticated social-communication).

\section{Factor structure}

There were no differences between the split-half samples in terms of age $(t(912)=0.8, p=0.4)$, sex (Fisher's exact test; $p=0.95)$, or repetitive behavior composite score $(t(912)=0.7, p=0.5)$. For the initial EFA sample $(n=$ 457), the KMO index indicated excellent overall sampling adequacy $(K M O=0.91)$. Visual inspection of scree plots suggested that either a three- or four-factor solution were most appropriate for the data. Rotated factor solutions for these models are presented in Tables 3 and 4.

The four-factor model was similar in composition to the conceptually derived model, with the exception of two items originally designated as "ritual and routine" loading on the "restricted behavior" factor (object arrangement, placement of objects). The three-factor model was similar in composition to the four-factor model but with items originally designated as "self-directed" loading with either "ritual and routine" or "restricted behavior." To assess the fit of the three- and four-factor models, two- and fivefactor models were also generated. The two-factor model was characterized by numerous cross-loading items and is not presented here. The five-factor model resulted in a pattern matrix resembling that for the four-factor model but with a fifth factor consisting of a single item that previously loaded with repetitive motor (repetitive use of toys and other objects).

Four models were subsequently tested through CFA on the second split-half sample $(n=457)$. Three models were derived from the EFA (four-, three-, and two-factor models), while the fourth was based on the original conceptually derived structure of the RBS-EC. The fivefactor model tested in the EFA phase was not examined through CFA given that one of its factors comprised a single item. Goodness-of-fit statistics for these four-factor models are presented in Table 5.

Overall, test indices indicated acceptable fit for the EFA-derived four-factor and three-factor models. The conceptually derived four-factor model, which included all original items, was acceptable in terms of RMSEA and SRMR statistics but just below the recommended range for the CFI. Fit statistics indicated that the twofactor model should be rejected.

\section{Discussion}

We developed a parent-report measure of restricted and repetitive behaviors (RRBs), specifically designed for use in early childhood, based on the general structure of the widely used Repetitive Behavior Scale-Revised [28]. Our intention in so doing was to create a developmentally appropriate behavioral measure capable of capturing quasidimensional information across a broad range RRBs. Once developed and assessed for content validity, we tested our 
Table 3 Rotated pattern matrix for four-factor solution from exploratory factor analysis

\begin{tabular}{|c|c|c|c|c|}
\hline Item heading & $\begin{array}{l}\text { Repetitive } \\
\text { motor }\end{array}$ & $\begin{array}{l}\text { Ritual and } \\
\text { routine }\end{array}$ & Restricted & Self-directed \\
\hline Torso & 0.93 & 0.04 & -0.01 & 0.01 \\
\hline Head & 0.88 & -0.02 & -0.01 & -0.03 \\
\hline Legs & 0.85 & -0.06 & 0.03 & -0.05 \\
\hline Arms, hand, or fingers & 0.84 & 0.07 & 0.03 & -0.04 \\
\hline $\begin{array}{l}\text { Arms/hand/fingers } \\
\text { on surfaces }\end{array}$ & 0.81 & 0.00 & 0.02 & 0.03 \\
\hline Locomotion & 0.79 & 0.00 & 0.00 & -0.02 \\
\hline Object use & 0.72 & -0.11 & 0.05 & 0.03 \\
\hline Vocalizations & 0.70 & 0.01 & 0.09 & 0.06 \\
\hline Mouthing objects & 0.50 & 0.04 & -0.03 & 0.15 \\
\hline Play & -0.02 & 0.78 & -0.02 & 0.00 \\
\hline Daily routine & -0.04 & 0.73 & -0.04 & 0.06 \\
\hline Change in others & 0.01 & 0.66 & -0.02 & 0.03 \\
\hline Mealtime & 0.06 & 0.61 & -0.01 & 0.03 \\
\hline New places & -0.09 & 0.58 & 0.10 & 0.05 \\
\hline Bedtime & 0.05 & 0.54 & 0.06 & -0.06 \\
\hline Social interactions & -0.05 & 0.53 & 0.10 & 0.09 \\
\hline Interruptions & 0.02 & 0.40 & 0.13 & 0.13 \\
\hline Visual inspection & -0.03 & -0.08 & 0.76 & 0.09 \\
\hline $\begin{array}{l}\text { Fascination with } \\
\text { movement }\end{array}$ & 0.02 & -0.13 & 0.71 & 0.18 \\
\hline $\begin{array}{l}\text { Interest in parts } \\
\text { of objects }\end{array}$ & -0.04 & -0.08 & 0.67 & 0.16 \\
\hline $\begin{array}{l}\text { Limited and intense } \\
\text { interest }\end{array}$ & 0.04 & 0.05 & 0.48 & 0.04 \\
\hline Stillness & -0.01 & 0.10 & 0.47 & -0.14 \\
\hline Sensory interests & 0.09 & 0.13 & 0.45 & -0.01 \\
\hline Media use & -0.01 & 0.22 & 0.40 & -0.08 \\
\hline Object attachment & -0.02 & 0.14 & 0.40 & -0.02 \\
\hline Placement of objects & 0.04 & 0.32 & 0.35 & -0.19 \\
\hline Arranging toys & 0.13 & 0.08 & 0.32 & -0.18 \\
\hline Hits self with object & 0.01 & 0.05 & -0.03 & 0.73 \\
\hline Hits self with body part & 0.09 & 0.08 & -0.20 & 0.72 \\
\hline Hits self against surface & 0.01 & 0.01 & 0.02 & 0.63 \\
\hline Pulls own hair & -0.02 & 0.14 & 0.04 & 0.32 \\
\hline $\begin{array}{l}\text { Scratches, pinches, } \\
\text { or pokes self }\end{array}$ & 0.01 & -0.09 & 0.20 & 0.32 \\
\hline Bites self & -0.05 & 0.02 & 0.10 & 0.19 \\
\hline Skin picking & 0.00 & 0.11 & 0.07 & 0.14 \\
\hline
\end{tabular}

Italics signify items belonging to a common factor

34-item measure (RBS-EC; Repetitive Behavior Scale for Early Childhood) in a community sample of 914 toddlers. The results suggest that the RBS-EC has good psychometric properties including strong overall internal consistency, adequate-to-strong internal consistency among
Table 4 Rotated pattern matrix for three-factor solution from exploratory factor analysis

\begin{tabular}{|c|c|c|c|}
\hline Item heading & $\begin{array}{l}\text { Repetitive } \\
\text { motor }\end{array}$ & $\begin{array}{l}\text { Ritual and } \\
\text { routine }\end{array}$ & Restricted \\
\hline Torso & 0.94 & 0.04 & -0.11 \\
\hline Head & 0.89 & -0.03 & -0.03 \\
\hline Legs & 0.84 & -0.08 & 0.00 \\
\hline Arms, hands, or fingers & 0.84 & 0.06 & 0.00 \\
\hline Arms/hands/fingers on surfaces & 0.81 & 0.00 & 0.03 \\
\hline Locomotion & 0.78 & 0.00 & -0.02 \\
\hline Object use & 0.73 & -0.11 & 0.06 \\
\hline Vocalizations & 0.71 & 0.02 & 0.11 \\
\hline Mouthing objects & 0.52 & 0.06 & 0.03 \\
\hline Play & -0.03 & 0.80 & -0.06 \\
\hline Daily routine & -0.04 & 0.77 & -0.06 \\
\hline Change in others & 0.01 & 0.68 & -0.04 \\
\hline Mealtime & 0.06 & 0.63 & -0.03 \\
\hline New places & -0.09 & 0.60 & 0.09 \\
\hline Social interactions & -0.04 & 0.56 & 0.12 \\
\hline Bedtime & 0.04 & 0.54 & 0.01 \\
\hline Interruptions & 0.03 & 0.43 & 0.16 \\
\hline Placement of objects & 0.00 & 0.29 & 0.25 \\
\hline Hits self with body part & 0.21 & 0.22 & 0.11 \\
\hline Pulls own hair & 0.03 & 0.21 & 0.18 \\
\hline Skin picking & 0.01 & 0.17 & 0.12 \\
\hline Visual inspection & -0.04 & -0.07 & 0.82 \\
\hline Fascination with movement & 0.03 & -0.11 & 0.80 \\
\hline Interest in parts of objects & -0.03 & -0.06 & 0.74 \\
\hline Limited and intense interests & 0.04 & 0.05 & 0.49 \\
\hline Sensory interests & 0.08 & 0.13 & 0.44 \\
\hline Stillness & -0.05 & 0.07 & 0.40 \\
\hline Object attachment & -0.04 & 0.13 & 0.38 \\
\hline Media use & -0.03 & 0.20 & 0.35 \\
\hline Scratches, pinches, or pokes self & 0.05 & -0.03 & 0.34 \\
\hline Hits self against surface & 0.11 & 0.14 & 0.28 \\
\hline Hits self with object & 0.13 & 0.20 & 0.27 \\
\hline Arranging toys/objects & 0.10 & 0.04 & 0.23 \\
\hline Bites self & -0.02 & 0.06 & 0.19 \\
\hline
\end{tabular}

Italics signify items belonging to a common factor

conceptually derived subscales, and strong test-retest reliability. As with previous studies of RRBs among young children $[15,16,29,47]$, we observed a wide range of response patterns which, as measured in total by the RBS$\mathrm{EC}$, suggest a high degree of inter-individual variability (Fig. 1).

Factorial validity was assessed by a split-half approach balancing exploratory and confirmatory factor analysis. We identified that a three- or four-factor model best fit 
Table 5 Confirmatory factor analysis model fit parameters for RBS-EC

\begin{tabular}{lllllll}
\hline Factors & $X^{2}$ & $d f$ & $p$ & CFI & RMSEA & SRMR \\
\hline $4^{\mathrm{a}}$ & 1181.2 & 489 & $<0.001$ & 0.88 & 0.056 & 0.057 \\
4 & 795.4 & 344 & $<0.001$ & 0.91 & 0.054 & 0.048 \\
3 & 674.3 & 272 & $<0.001$ & 0.92 & 0.057 & 0.048 \\
2 & 976.6 & 298 & $<0.001$ & 0.86 & 0.071 & 0.070 \\
\hline
\end{tabular}

CFI comparative fit index, RMSEA root mean square error of approximation, SRMR standardized root mean square residual

${ }^{a}$ Conceptually derived four-factor model with all items

the data, with the latter aligning well with the original conceptual organization of the measure. It would appear that the RBS-EC may be used with or without the subscale measuring self-directed behaviors (four or three factors, respectively). Inclusion of this subscale may be of particular relavance to children with or at-risk for a neurodevelopmental disorder given that self-injurious behavior is both more common and a likely target of intervention/prevention among this population $[2,3,13]$. When considered along with initial content validity checks, the results of the factor analyses suggest that test scores from the RBS-EC reflect the construct of restricted and repetitive behavior. Construct validity of the RBS-EC was further evidenced by preliminary tests of convergent and discriminant validity. Scores from the measure significantly correlated with repetitive behavior scores derived from the vr-RSB [40] but showed little overlap with its video-referenced social behavior subscale. We did observe, however, a modest but statistically significant correlation between the RBS-EC and the social-communication summary score from the vr-RSB. The effect size of this relationship was relatively weak, accounting for less than $5 \%$ of shared variance. However, while potentially an artifact related to sample size, there is some evidence that RRBs and social-communication skills may be inversely associated during toddlerhood [27, 33], and conceptually, there is little reason to assume a purely orthogonal relationship between these constructs.

Despite their ubiquity in early childhood, there is evidence that restricted and repetitive behaviors may differentiate children with and without developmental concerns such as autism during toddlerhood $[26,27,33,36,48]$ and as early as the first year of life $[49,50]$. What is not clear is whether RRBs associated with early atypical development belong to the same class of behavior as those associated with typical development. Stated differently, are repetitive behaviors associated with atypical early development the extreme end of a continuum of behavioral output characteristic of all children, or do they qualitatively differ with regard to underlying function and mechanism? While we cannot speak directly to these questions, data from the present study provides some support to the position that repetitive behaviors in early childhood represent a dimensional behavioral feature given that we observed a continuum of RRBs in our sample of toddlers. This point is illustrated by the distribution of responses shown in Fig. 1. For those children with or at risk for neurodevelopmental disorders, the expected pattern of RRBs may be pronounced, follow an altered trajectory, and fail to resolve as more adaptive behaviors come online [13, 20]. We posit that these children and others who are atypically developing

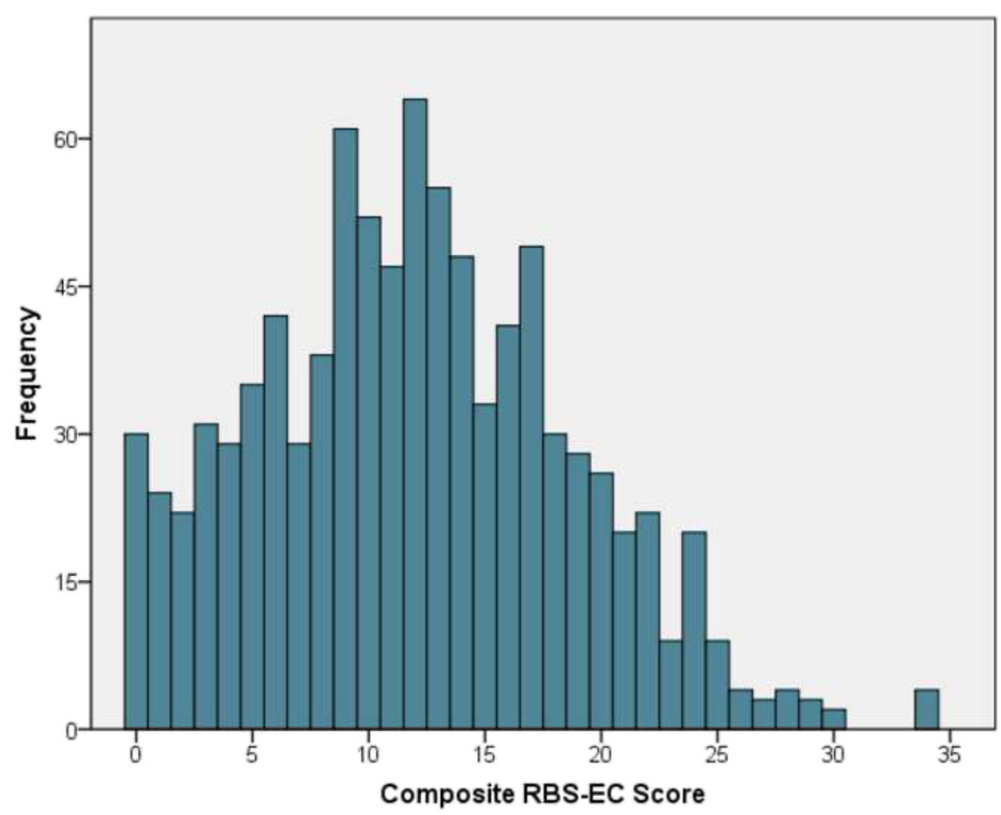

Fig. 1 Response distribution for total topographies endorsed 
will fall disproportionately into the right tail of distribution illustrated in Fig. 1. Follow-up work will be required to fully address this issue.

The RBS-EC was developed for use in early childhood, acknowledging the behavioral variability that occurs between infancy and school age. While some aspects of this scale may be appropriate for use in a child 1 year old or younger-the repetitive motor subscale, for example, might be applied to children as young as 1-2 months $[12,14]$-others would clearly not be applicable to this age group. We expect items such as "restricted use of media" to be quite relevant to the behavioral repertoire of preschool and elementary school aged children but substantially less so for infants. As the present results pertain only to toddlers, the upper- and lower-age limits of the RBS-EC are unknown. We designed the measure considering a provisional upper-age limit proximal to early school age. This was based in part on previous reports suggesting that RRBs among most children wane after age 5 and reach negligible levels by early adolescence $[15,17$, $51,52]$. However, as there is very little published literature pertaining to normative patterns of RRBs in school aged children, it is difficult to estimate the suitability of the RBS-EC for this age group. It will therefore be necessary to directly assess the validity and psychometric properties of the RBS-EC outside of toddlerhood to establish developmental variation in factor structure as well as upper and lower-age boundaries.

Some conceptual models of RRBs have grouped repetitive motor behaviors with self-directed (or self-injurious) behaviors, describing these as "lower order" or "sensorymotor" given shared qualities related to topography [53]. There is also a long-standing hypothesis that motor stereotypies may function as precursors of self-injury among children with or at-risk for a neurodevelopmental disorder [54, 55], and there is some empirical support to this effect [56]. In this study, however, we did not identify any circumstance under which these subtypes of repetitive behavior loaded together. Indeed, when items were constrained to a two-factor model, the majority of selfdirected items loaded with ritualistic and routine behaviors. Our results are consistent with other studies finding that self-injurious behaviors occur in typically developing toddlers absent elevated stereotypy [57] and that these subtypes of RRB are a distinct class of behavior from motor stereotypy in children with autism $[31,32]$. It is possible that the construct of proto-self-injurious behavior has been over-extended to include any motor stereotypy, when a more narrow definition related to body-directed, pre-injurious topographies is warranted [39].

The present work was based on a community sample of toddlers. It is likely that these children are characterized by a continuum of cognitive and adaptive functioning and not just so-called typical development. For example, our sample includes a range of birth weights and gestational ages that reflect the US population. However, we cannot be certain of the cognitive or adaptive behavioral characteristics of our sample as these measures were not collected. We are therefore unable to speak to the relationship of RRBs to such variables. Follow-up work should collect additional cognitive and behavioral data as well as enrich for target populations who have been identified as having a neurodevelopmental disorder. Doing so would help clarify where individuals characterized by atypical development fall on the continuum of RRBs measured by the RBS-EC and contribute to assessment of possible clinical utility and criterion-related validity. This is an essential next step given that the present work cannot directly speak to the performance of the RBS-EC among children with neurodevelopmental disorders. Future work might also further assess construct validity by comparing the RBS-EC with similar measures such as the RBS-R or RBQ-2 $[28,29]$ and clarify upper- and lower-age limits among children who are typically developing as well as children with neurodevelopmental disorders.

\section{Conclusions}

In most circumstances and for the majority of children, some degree of restricted and repetitive behavior is both adaptive and expected. There appears, as indicated by this and similar studies of young children, a continuum of such behavior in the general population. What is not yet known are the development implications of individual differences in these behaviors early in life. It has become increasingly clear that early deviations or excesses in RRBs may indicate risk for disorders of neurodevelopment. Improved characterization of patterns and trajectories of restricted and repetitive behavior during early childhood may enhance efforts to identify at-risk children and delineate clinically meaningful subgroups based on shared and specific phenotypes.

\section{Additional files}

Additional file 1: Instructions and sample items from the RBS-EC. (DOCX $25 \mathrm{~kb}$ )

Additional file 2: Figure S1. Response distributions for RBS-EC subscale topographies endorsed. (TIF $88 \mathrm{~kb}$ )

Additional file 3: Figure S2. Response distributions for RBS-EC subscale frequency scores. (TIF $109 \mathrm{~kb}$ )

\footnotetext{
Acknowledgements

We wish to thank Elayne Teska, Carolyn Lasch, and the families who contributed data to this research.
}

\section{Funding}

This research was supported by grants K01 MH101653 (Wolff) and R01 $\mathrm{MH} 104324$ (Elison) from the National Institute for Mental Health. The content is solely the responsibility of the authors and does not necessarily represent the official views of the National Institutes of Health. 


\section{Authors' contributions}

JJW was involved in measure development, study design, data analysis, interpretation of the data, and drafting of the manuscript. BAB was involved in measure development, interpretation of the data, and manuscript preparation. JTE was involved in study design, data collection, interpretation of the data, and manuscript preparation. All authors read and approved the final manuscript.

\section{Competing interests}

The authors declare that they have no competing interests.

\section{Ethics approval and consent to participate}

Study procedures were approved by the University of Minnesota Institutional Review Board (\#1501561261) and informed written consent was obtained from each participant.

\section{Author details}

'Department of Educational Psychology, University of Minnesota, Minneapolis, MN, USA. ${ }^{2}$ Department of Allied Health Sciences, University of North Carolina, Chapel Hill, NC, USA. ${ }^{3}$ Institute of Child Development, University of Minnesota, Minneapolis, MN, USA.

Received: 5 April 2016 Accepted: 17 July 2016

Published online: 02 August 2016

\section{References}

1. Moss J, Oliver C, Arron K, Burbidge C, Berg K. The prevalence and phenomenology of repetitive behavior in genetic syndromes. J Autism Dev Disord. 2009;39:572-88.

2. Flores $C G$, Valcante $G$, Guter $S$, Zaytoun A, Wray E, Bell L, Jacob S, Lewis MH, Driscoll DJ, Cook EH, Kim S-J. Repetitive behavior profiles: consistency across autism spectrum disorder cohorts and divergence from Prader-Willi syndrome. J Neurodev Disord. 2011;3:316-24.

3. Wolff J, Bodfish JW, Hazlett HC, Lightbody AA, Reiss AL, Piven J. Evidence of a distinct behavioral phenotype in young boys with fragile $\mathrm{X}$ syndrome and autism. J Am Acad Child Adolesc Psychiatry. 2012;51:1324-32.

4. Abramowitz JS, Jacoby RJ. Obsessive-compulsive and related disorders: a critical review of the new diagnostic class. Annu Rev Clin Psychol. 2015;11:165-86

5. Zucker NL, Losh M, Bulik CM, LaBar KS, Piven J, Pelphrey KA. Anorexia nervosa and autism spectrum disorders: guided investigation of social cognitive endophenotypes. Psychol Bull. 2007;133:976-1006.

6. Fasano A, Petrovic I. Insights into pathophysiology of punding reveal possible treatment strategies. Mol Psychiatry. 2010;15:560-73.

7. Freeman RD, Soltanifar A, Baer S. Stereotypic movement disorder: easily missed. Dev Med Child Neurol. 2010:52.733-8.

8. Ruzzano L, Borsboom D, Geurts HM. Repetitive behaviors in autism and obsessive-compulsive disorder: new perspectives from a network analysis. J Autism Dev Disord. 2015;45:192-202

9. Eilam D, Zor R, Szechtman H, Hermesh H. Rituals, stereotypy and compulsive behavior in animals and humans. Neurosci Biobehav Rev. 2006;30:456-71.

10. Barrett SL, Uljarević M, Baker EK, Richdale AL, Jones CRG, Leekam SR. The adult repetitive behaviours questionnaire-2 (RBQ-2A): a self-report measure of restricted and repetitive behaviours. J Autism Dev Disord. 2015:45:3680-92.

11. Berkson G, Rafaeli-Mor N, Tarnovsky S. Body-rocking and other habits of college students and persons with mental retardation. Am J Ment Retard. 1999;104:107-16.

12. Thelen E. Rhythmical stereotypies in normal human infants. Anim Behav. 1979;27(Pt 3):699-715.

13. Hoch J, Spofford L, Dimian A, Tervo R, MacLean WE, Symons FJ. A direct comparison of self-injurious and stereotyped motor behavior between preschool-aged children with and without developmental delays. J Pediatr Psychol. 2015:41:566-72.

14. MacLean WE, Ellis DN, Galbreath HN, Halpern LF, Baumeister AA. Rhythmic motor behavior of preambulatory motor impaired, Down syndrome and nondisabled children: a comparative analysis. J Abnorm Child Psychol. 1991:19:319-30

15. Evans DW, Leckman JF, Carter A, Reznick JS, Henshaw D, King RA, Pauls D. Ritual, habit, and perfectionism: the prevalence and development of compulsive-like behavior in normal young children. Child Dev. 1997;68:58-68.
16. Zohar AH, Felz L. Ritualistic behavior in young children. J Abnorm Child Psychol. 2001;29:121-8.

17. Foster LG. Nervous habits and stereotyped behaviors in preschool children. J Am Acad Child Adolesc Psychiatry. 1998:37:711-7.

18. Tröster H. Prevalence and functions of stereotyped behaviors in nonhandicapped children in residential care. J Abnorm Child Psychol. 1994:22:79-97.

19. Harris KM, Mahone EM, Singer HS. Nonautistic motor stereotypies: clinical features and longitudinal follow-up. Pediatr Neurol. 2008:38:267-72.

20. Evans DW, Kleinpeter FL, Slane MM, Boomer KB. Adaptive and maladaptive correlates of repetitive behavior and restricted interests in persons with down syndrome and developmentally-matched typical children: a two-year longitudinal sequential design. PLoS One. 2014;9, e93951.

21. Lord C, Rutter M, Couteur A. Autism diagnostic interview-revised: a revised version of a diagnostic interview for caregivers of individuals with possible pervasive developmental disorders. J Autism Dev Disord. 1994:24:659-85.

22. Scahill L, Riddle MA, McSwiggin-Hardin M, Ort SI, King RA, Goodman WK, Cicchetti D, Leckman JF. Children's Yale-Brown obsessive compulsive scale: reliability and validity. J Am Acad Child Adolesc Psychiatry. 1997;36:844-52.

23. Goodwin MS, Intille SS, Albinali F, Velicer WF. Automated detection of stereotypical motor movements. J Autism Dev Disord. 2011;41:770-82.

24. Karch D, Kang K-S, Wochner K, Philippi H, Hadders-Algra M, Pietz J, Dickhaus $\mathrm{H}$. Kinematic assessment of stereotypy in spontaneous movements in infants. Gait Posture. 2012:36:307-11.

25. Newell KM, Bodfish JW. Dynamical origins of stereotypy: relation of postural movements during sitting to stereotyped movements during body rocking. Am J Ment Retard. 2007;112:66-75.

26. Watt N, Wetherby AM, Barber A, Morgan L. Repetitive and stereotyped behaviors in children with autism spectrum disorders in the second year of life. J Autism Dev Disord. 2008;38:1518-33.

27. Ozonoff S, Macari S, Young GS, Goldring S, Thompson M, Rogers SJ Atypical object exploration at 12 months of age is associated with autism in a prospective sample. Autism. 2008:12:457-72.

28. Bodfish JW, Symons FJ, Parker DE, Lewis MH. Varieties of repetitive behavior in autism: comparisons to mental retardation. J Autism Dev Disord. 2000;30:237-43.

29. Leekam S, Tandos J, McConachie H, Meins E, Parkinson K, Wright C, Turner M, Arnott B, Vittorini L, Le Couteur A. Repetitive behaviours in typically developing 2-year-olds. J Child Psychol Psychiatry. 2007:48:1131-8.

30. Esbensen AJ, Seltzer MM, Lam KSL, Bodfish JW. Age-related differences in restricted repetitive behaviors in autism spectrum disorders. J Autism Dev Disord. 2009:39:57-66

31. Bishop SL, Hus V, Duncan A, Huerta M, Gotham K, Pickles A, Kreiger A, Buja A, Lund S, Lord C. Subcategories of restricted and repetitive behaviors in children with autism spectrum disorders. J Autism Dev Disord. 2013;43: 1287-97.

32. Mirenda P, Smith IM, Vaillancourt T, Georgiades S, Duku E, Szatmari P, Bryson S, Fombonne E, Roberts W, Volden J, Waddell C, Zwaigenbaum L. Validating the repetitive behavior scale-revised in young children with autism spectrum disorder. J Autism Dev Disord. 2010;40:1521-30.

33. Wolff JJ, Botteron KN, Dager SR, Elison JT, Estes AM, Gu H, Hazlett HC, Pandey J, Paterson SJ, Schultz RT, Zwaigenbaum L, Piven J. Longitudinal patterns of repetitive behavior in toddlers with autism. J Child Psychol Psychiatry. 2014;55:945-53.

34. Lam KSL, Aman MG. The repetitive behavior scale-revised: independent validation in individuals with autism spectrum disorders. J Autism Dev Disord. 2007;37:855-66.

35. Honey E, McConachie $\mathrm{H}$, Turner M, Rodgers J. Validation of the repetitive behaviour questionnaire for use with children with autism spectrum disorder. Res Autism Spectr Disord. 2012;6:355-64.

36. Elison JT, Wolff JJ, Reznick JS, Botteron KN, Estes AM, Gu H, Hazlett HC, Meadows AJ, Paterson SJ, Zwaigenbaum L, Piven J. Repetitive behavior in 12-month-olds later classified with autism spectrum disorder. J Am Acad Child Adolesc Psychiatry. 2014;53:1216-24.

37. Boyd BA, Baranek GT, Sideris J, Poe MD, Watson LR, Patten E, Miller $H$ Sensory features and repetitive behaviors in children with autism and developmental delays. Autism Res. 2010:3:78-87.

38. Symons FJ, Sperry LA, Dropik PL, Bodfish JW. The early development of stereotypy and self-injury: a review of research methods. J Intellect Disabil Res. 2005;49(Pt 2):144-58.

39. Berkson G, Tupa M, Sherman L. Early development of stereotyped and self-injurious behaviors: I. Incidence. Am J Ment Retard. 2001;106:539-47. 
40. Marrus N, Glowinski AL, Jacob T, Klin A, Jones W, Drain CE, Holzhauer KE, Hariprasad V, Fitzgerald RT, Mortenson EL, Sant SM, Cole L, Siegel SA, Zhang Y, Agrawal A, Heath AC, Constantino JN. Rapid video-referenced ratings of reciprocal social behavior in toddlers: a twin study. J Child Psychol Psychiatry. 2015;56:1338-46.

41. Fenson L, Marchman VA, Thal DJ, Dale PS, Reznick JS, Bates E. MacArthur-Bates communicative development inventories. 2nd ed. Baltimore: Paul H. Brookes; 2007.

42. Weigold A, Weigold IK, Russell EJ. Examination of the equivalence of self-report survey-based paper-and-pencil and internet data collection methods. Psychol Methods. 2013;18:53-70.

43. Singer $E$, Ye $C$. The use and effects of incentives in surveys. Ann Am Acad Pol Soc Sci. 2012;645:112-41.

44. Constantino JN, Gruber CP. Social responsiveness scale, second edition (SRS-2). Torrance: Western Psychological Services; 2012

45. Hu L, Bentler PM. Cutoff criteria for fit indexes in covariance structure analysis: conventional criteria versus new alternatives. Struct Equ Model A Multidiscip J. 1999;6:1-55.

46. McDonald RP, Ho M-HR. Principles and practice in reporting structural equation analyses. Psychol Methods. 2002;7:64-82.

47. Arnott B, McConachie H, Meins E, Fernyhough C, Couteur AL, Turner M, Parkinson $\mathrm{K}$, Vittorini L, Leekam $\mathrm{S}$. The frequency of restricted and repetitive behaviors in a community sample of 15-month-old infants. J Dev Behav Pediatr. 2010;31:223-9.

48. Kim SH, Lord C. Restricted and repetitive behaviors in toddlers and preschoolers with autism spectrum disorders based on the autism diagnostic observation schedule (ADOS). Autism Res. 2010;3:162-73.

49. Watson LR, Baranek GT, Crais ER, Steven Reznick J, Dykstra J, Perryman T. The first year inventory: retrospective parent responses to a questionnaire designed to identify one-year-olds at risk for autism. J Autism Dev Disord. 2007;37:49-61.

50. Werner E, Dawson G, Munson J, Osterling J. Variation in early developmental course in autism and its relation with behavioral outcome at 3-4 years of age. J Autism Dev Disord. 2005;35:337-50.

51. Zohar AH, Bruno R. Normative and pathological obsessive-compulsive behavior and ideation in childhood: a question of timing. J Child Psychol Psychiatry. 1997:38:993-9.

52. Glenn S, Cunningham C, Nananidou A. A cross-sectional comparison of routinized and compulsive-like behaviours in typical children aged from 2 to 11 years. Eur J Dev Psychol. 2012;9:614-30.

53. Turner M. Annotation: repetitive behaviour in autism: a review of psychological research. J Child Psychol Psychiatry. 1999;40:839-49.

54. Guess D, Carr E. Emergence and maintenance of stereotypy and self-injury. Am J Ment Retard. 1991;96:299-319.

55. Oliver C, Richards C. Practitioner review: self-injurious behaviour in children with developmental delay. J Child Psychol Psychiatry. 2015;56:1042-54.

56. Rojahn J, Barnard-Brak L, Medeiros K, Schroeder SR. Stereotyped behaviours as precursors of self-injurious behaviours: a longitudinal study with infants and toddlers at risk for developmental delay. J Intellect Disabil Res. 2016:60:156-66.

57. Richler J, Bishop SL, Kleinke JR, Lord C. Restricted and repetitive behaviors in young children with autism spectrum disorders. J Autism Dev Disord. 2007;37:73-85.

\section{Submit your next manuscript to BioMed Central and we will help you at every step:}

- We accept pre-submission inquiries

- Our selector tool helps you to find the most relevant journal

- We provide round the clock customer support

- Convenient online submission

- Thorough peer review

- Inclusion in PubMed and all major indexing services

- Maximum visibility for your research

Submit your manuscript at www.biomedcentral.com/submit 